\title{
Territórios e comunidades tradicionais ${ }^{1}$
}

\section{Territories and traditional communities}

\section{Antonio Carlos Sant'ana Diegues ${ }^{2}$}

Estou muito contente de estar aqui em Matinhos pela primeira vez. Mudei meu tema de exposição nesta noite porque visitei um porto de pescadores-caiçaras aqui em Matinhos, e a conversa com eles me reportou há trinta anos quando comecei a fazer meu mestrado na região de Iguape e Cananéia. Aí, em 1970 me encontrei pela primeira vez com pescadores de Matinhos, que vinham com suas canoas grandes, de proa alta, pescar durante uma temporada na Ilha Comprida, defronte à cidade de Iguape, no litoral sul de São Paulo. Os pescadorescaiçaras locais os chamavam de "andorinhas", porque eles vinham no verão, pescavam e depois voltavam para cá. No meu imaginário esses "andorinhas" eram pescadores corajosos e experientes pois afrontavam o mar em canoas de um tronco só, o que despertou minha curiosidade em conhecer a cidade de onde eles vinham. Esta é minha primeira visita a Matinhos, mas, de alguma forma, eu a conhecia através de seus pescadores. Pude constatar que Matinhos continua com sua tradição pesqueira, que, como ocorre com outras cidades, não tem consciência do patrimônio cultural de que dispõe e que a torna distinta de tantas outras onde esse modo de vida está desaparecendo.

Ademais, em minhas conversas com pescadores que cuidavam de seus petrechos de pesca, próximo ao Mercado Municipal de Pescado, encontrei um deles que tinha ido, naquele período, pescar na Ilha Comprida, o que revela a antiguidade dessa atividade de importância tanto cultural como social para a cidade, e que a tradição continua viva. Hoje, essas canoas fantásticas são feitas de fibra de vidro, no formato das anteriores, ainda que maiores.

Para minha surpresa, constatei que existe uma única canoa das antigas em uso. Acredito que é dever desta cidade e desta Universidade resguardar e valorizar essa tradição e sua memória através de um centro cultural marítimo onde essa canoa resistente ao tempo possa ser conservada e exposta à visitação. Acho que ela merece um lugar importante na cidade, aberta à visitação pública (incluída a dos turistas) com a descrição de quão importante foi e é a pesca para esta cidade em termos do aporte dos peixes à alimentação local e da

\footnotetext{
${ }^{1}$ Palestra proferida na mesa de encerramento "Desenvolvimento Territorial Sustentável: um diálogo interdisciplinar", do I Simpósio Brasileiro de Desenvolvimento Territorial Sustentável (UFPR), realizado em 29 e 30 de outubro de 2015, na cidade de Matinhos (PR).

${ }^{2}$ Doutor em Ciências Sociais (USP). Professor da Universidade de São Paulo (USP). E-mail: antoniodiegues69@gmail.com.
} 
própria cultura e modo de vida que os pescadores-caiçaras desenvolvem. Devo também ressaltar que o Mercado Municipal de Peixes, ao contrário de muitas outras cidades turísticas, vende somente as espécies de pescado capturadas por esses pescadores em seu território marítimo-pesqueiro. Há que se ressaltar que um número expressivo de mulheres que têm bancas de peixe no Mercado são familiares de pescadores. Aliás, em muitas comunidades, sobretudo do Norte/Nordeste, há pescadoras como presidentes de associações, desempenhando um protagonismo importante na luta pelos direitos de seus associados.

Nesse contexto, é fundamental compreender o sentido da importância da noção de território pesqueiro que deve ser resguardado das ameaças representadas pela expansão urbana, pelas atividades da pesca industrial, pela implantação de áreas protegidas integrais e de outras atividades que limitam a área de pesca tradicional.

É nesse território onde as atividades pesqueiras tradicionais se desenvolvem, onde se realizam as relações sociais entre os pescadores, onde se produz o vasto conhecimento tradicional transmitido aos jovens pela oralidade, onde os aspectos simbólicos são gerados através das inúmeras histórias que ouvi nesse porto: sobre naufrágios de canoas; sobre a habilidade que tem que ter um pescador para fazer face ao mar, muitas vezes perigoso à navegação e que faz da pesca um ato de coragem... Esse saber/fazer tradicional, ainda tão desconhecido no âmbito do Estado e das próprias universidades e que se refere ao conhecimento sobre as correntes marítimas, sobre as fases da lua apropriadas para a pesca, sobre os ventos favoráveis e desfavoráveis, a migração e reprodução das espécies de pescado, as artes de pesca necessárias a cada tipo de peixe. Sem esses conhecimentos as saídas para a pesca poderiam se transformar num fracasso e num perigo à própria vida dos pescadores. Raramente os pescadores são chamados pelas autoridades para contribuir com seu conhecimento para as portarias que regulamentam suas atividades, como se as ciências naturais fossem suficientes para garantir a reprodução das espécies. Essa falta de participação dos pescadores foi revelado, por exemplo, na instituição do Parque Nacional da Ilha dos Currais, área fundamental para as atividades dos pescadores artesanais caiçaras e que ainda hoje é fonte de conflitos. Há de ressaltar, no entanto, que com o apoio de mestrandos desta Universidade, os pescadores conseguiram uma autorização de pesca durante cerca de três meses ao ano nos arredores desse parque nacional.

A atitude autoritária de órgãos de conservação é ainda mais grave quando no Sistema Nacional de Unidades de Conservação (SNUC) existem outras categorias como a Reserva Extrativista Costeira ou a Reserva de Desenvolvimento Sustentável, que são mais adequadas para proteger tanto a diversidade biológica quanto as atividades pesqueiras tradicionais. Por 
quê? Porque a mentalidade reinante em muitos órgãos ambientais é que esses territórios marítimos são vazios, o que contradiz o fato de que neles existem atividades pesqueiras que podem ser compatíveis com a conservação biológica. Essa atitude é recorrente não só aqui no litoral do Paraná, mas em outros territórios marítimos ao longo do litoral brasileiro. Essa estratégia autoritária tem gerado conflito também em comunidades tradicionais que têm seu território na Mata Atlântica e que, ao contrário do agronegócio, têm um impacto reduzido na diversidade das matas. Muitas dessas comunidades têm sido expulsas de seus sítios no litoral ou proibidas de fazer suas pequenas roças, responsáveis pela produção de farinha, por exemplo, alimentação básica dessas comunidades. Com a proibição das roças desaparece o uso do mutirão, base da solidariedade social e das atividades culturais como o fandango. Essas pessoas acabam indo para a periferia das nossas cidades litorâneas, vivendo em favelas e na marginalidade social.

Muito frequentemente esses pescadores sofrem discriminação quanto à sua cultura e modo de vida, entendido como inadequado para a produção de renda na sociedade moderna.

Outras pessoas, algumas da área acadêmica, acham que pelo fato dos pescadores hoje usarem canoas de fibra não são mais pertencentes às comunidades tradicionais. Essas mudanças tecnológicas fazem parte do fato de que essas comunidades não são isoladas e que podem absorver elementos da modernidade sem que sua cultura e modo de vida deixem de ser tradicionais.

A cultura se adapta, transforma-se, mas mantém um núcleo fundamental de seu modo de vida e de sua relação com o mar, além da afirmação de sua identidade. Então não é o tamanho de embarcação, não é o tipo de embarcação, e sim certas variáveis que são muito mais importantes como a autonomia desses pescadores em definir onde e quando pescar, de manter seu conhecimento e práticas tradicionais de pesca, o fato de, em geral, serem donos ou parceiros de seus barcos e instrumentos de pesca, o uso da mão de obra familiar ou de membros de sua comunidade remunerados pelo sistema de parte e quinhões da produção comunitária, entre outras características socioculturais.

Quando estudei os pescadores artesanais da Noruega, nos anos 1980, constatei que tinham os barcos muito maiores do que os nossos, com radar, redes mais sofisticadas, mas se consideravam pescadores artesanais porque eram embarcação de propriedade familiar. A pesca deixa de ser artesanal; a propriedade da embarcação é de empresas de pesca que controlam toda a atividade de captura e beneficiamento do pescado.

Ainda no que se refere ao território marítimo, é importante afirmar que nele existem várias marcas, caminhos que levam aos pesqueiros conhecidos pelos pescadores. Esses 
pesqueiros, em geral, de fundo do mar, são marcas, sinais onde estão os cardumes, posses que, portanto, fazem parte desse território. Como afirmei anteriormente, esse território não é só um território de produção material, mas é um território que produz relações sociais, de amizade, às vezes de conflito, que produz conhecimentos, simbologias, histórias de tempestades, às vezes naufrágios, que fazem de Matinhos um exemplo importante de patrimônio material e imaterial de comunidades marítimas no Brasil.

Esse patrimônio muitas vezes não é sequer reconhecido pelas autoridades em todos os níveis e partem um pouco do preconceito anteriormente mencionado de que essas comunidades não têm história porque são analfabetas, não têm cultura escrita, o que revela um desconhecimento do que é cultura ou que ela está reservada às elites urbanas. Na verdade, essa cultura da oralidade é ainda patrimônio de milhares de outros povos e comunidades tradicionais através do mundo. O importante nessas culturas é sua diversidade de formas de vida, idiomas, formas de apropriação do território. Essa diversidade cultural se manifesta, por exemplo, no litoral paranaense e paulista onde convivem comunidades quilombolas, de pescadores-caiçaras, comunidades indígenas, como se têm aqui na Ilha Cotinga, que começam a se organizar em fóruns de povos e comunidades tradicionais que lutam pelo seu reconhecimento como culturas, tendo identidades próprias. Além disso, nos últimos anos constata-se um "ressurgimento" de demonstrações das culturas tradicionais ao longo do litoral Sudeste, sobretudo no Paraná, São Paulo e Rio de Janeiro, com o aparecimento de novos grupos de fandango, de caravanas de Bandeira do Divino transportada em canoas entre Cananéia e o litoral paranaense, de grupos de Reisados, de jongos quilombolas, congadas de cantos Guarani como ficou amplamente documentada no V Volume da Enciclopédia Caiçara: Festas, Lendas e Mitos Caiçaras (Nupaub, Ed. Hucitec, 2006). É importante ressaltar que, recentemente, o fandango do Paraná e São Paulo foi reconhecido pelo IPHAN como Patrimônio Imaterial Brasileiro. Estamos propondo que também a canoa caiçara seja reconhecida como patrimônio material do Brasil.

Parece-nos, no entanto, que esses territórios marítimo-terrestres dos povos e comunidades tradicionais devem ser ocupados e seus direitos defendidos sobretudo pelas organizações dos próprios povos e comunidades e seus aliados, como instituições de ensino e pesquisa, ONGs socioambientalistas, entre outras. Na Constituição de 1988, a mobilização dos pescadores resultou na aprovação de alguns direitos, sobretudo o de ter organizações próprias como sindicatos, aposentadoria etc. A mobilização também foi importante na construção da Comissão Nacional de Povos e Comunidades Tradicionais (2006) e da Política Nacional de Desenvolvimento Sustentável dos Povos e Comunidades Tradicionais (2007), 
que os define como "grupos culturalmente diferenciados e que se reconhecem como tais, que possuem formas próprias de organização social, que ocupam e usam territórios e recursos naturais como condição para sua reprodução cultural, social, ancestral e econômica, utilizando conhecimentos, inovações e práticas gerados e transmitidos pela tradição".

Esse mesmo documento define territórios tradicionais como "espaços necessários à reprodução cultural, social e econômica dos povos e comunidades tradicionais, sejam eles utilizados de forma permanente ou temporária (...)".

A partir de declaração da Política dos Povos e comunidades tradicionais em 2007, as comunidades caiçaras começaram a fazer parte de uma aliança de povos e comunidades tradicionais através de fóruns hoje existentes no litoral de São Paulo, do sul fluminense e do Vale do Ribeira (SP), nos quais participam organizações de comunidades quilombolas, indígenas, caiçaras, caboclas, entre outras. Esses fóruns estão se tornando instrumentos de aumento de sua visibilidade social e política, sendo apoiados por ONGs socioambientalistas, institutos de pesquisa e dos Pontos de Cultura do Ministério da Cultura.

É verdade também que nos últimos cinco anos houve retrocessos em termos de políticas públicas “desenvolvimentistas" que não respeitam esses territórios, em virtude do avanço do agronegócio sobre terras indígenas e de comunidades tradicionais, da construção de mega-hidroelétricas, de avanços sobre territórios pesqueiros por parte de empresas de exploração de petróleo, mineradoras, portos, especulação imobiliária, empresas de pesca e de cultivo de camarão etc. No entanto, essas ameaças também têm gerado reações por parte de movimentos organizados, como o do Movimento de Pescadores e Pescadoras, que têm atuado na defesa de territórios e direitos restringidos por uma política neoliberal e de pressões do atual Congresso Nacional.

Nota-se também algumas iniciativas pioneiras por parte de Defensorias Públicas e do Ministério Público, que recentemente se juntaram para contestar as licenças ambientais do Ibama para a expansão do polo petrolífero em São Sebastião (SP).

É também promissor o fato da Defensoria Pública da União Federal e Estadual do Paraná terem ajuizado em abril de 2015 uma ação civil pública ( $\mathrm{n}^{\circ}$ 500074288.2015.4.04.7008-PR) em face do ICMbio e aceita pela Justiça Federal (Seção Judiciária, $1^{\text {a }}$ Vara Federal de Paranaguá), assegurando ao Mopear - Movimento de Pescadores e Pescadoras do Paraná - seu direito a participar efetivamente do Plano de Manejo do Parque Nacional de Superagui, no litoral paranaense. Além disso, o Juiz Federal utiliza a Convenção 169 da Organização Internacional do Trabalho, entre outros dispositivos, para garantir os direitos das comunidades. Tenho certeza que essa decisão justa e corajosa pode criar um 
precedente histórico importante na defesa dos direitos sociais dos pescadores artesanais.

Em nível internacional, além das Convenções da Unesco, como a da Proteção e Promoção da Diversidade das Expressões Culturais do Patrimônio Material (2005), ratificadas (2006) e promulgadas (2007) pelo Brasil, a Convenção 169 da OIT - Organização Internacional do Trabalho - é, sem dúvida, o documento que pode melhor resguardar os direitos territoriais dos povos indígenas e comunidades tradicionais. Ela foi ratificada pelo Decreto Legislativo $\mathrm{n}^{\circ}$ 143, de 20 de junho de 2002, e tornada eficaz pelo Decreto Presidencial $\mathrm{n}^{\mathrm{o}}$ 5.071, de 19 de abril de 2004. Ela começa a ser utilizada por instâncias jurídicas na defesa dos direitos dos povos e comunidades tradicionais.

É importante também enfatizar novas modalidades de garantia e uso dos territórios desses povos e comunidades tradicionais através de modalidades apresentadas pelo Incra Instituto Nacional de Colonização e Reforma Agrária, como o PAE - Projeto de Assentamento Agroextrativista, o PAF - Projeto de Assentamento Florestal, e o Projeto de Desenvolvimento Sustentável.

Além disso, a Secretaria do Patrimônio da União (SPU) instituiu o Termo de Autorização de Uso Sustentável (TAUS), e Concessão de Direito Real de Uso (CDRU), regulamentado pela Portaria $n^{\circ} 89$, de abril de 2010, disciplinando o uso e o aproveitamento dos imóveis da União na orla marítima e fluvial em favor das comunidades tradicionais.

É encorajador que esses últimos instrumentos estejam sendo agora utilizados pelo Ministério Público Estadual e Federal para garantir direitos territoriais a algumas comunidades da Ilha Bela (2015), garantindo, sobretudo, a autonomia delas na gestão de seu território tradicional.

Nós, da Universidade, temos um papel importante no apoio aos direitos sociais e territoriais dos povos e comunidades tradicionais. Sei que esta Universidade Federal do Paraná -Setor Litoral dá grande importância aos trabalhos de extensão universitária nas comunidades locais e isso é fundamental não somente para a formação acadêmica, como também para a formação de cidadãos conscientes da realidade do país em que vivemos.

Texto recebido em 11/11/2015. Autor convidado. 